\title{
RANCANG BANGUN APLIKASI BUDIDAYA PERIKANAN BERBASIS MOBILE "NUFARM"
}

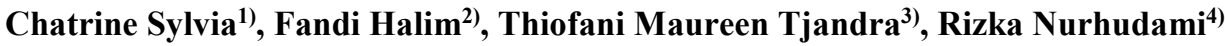 \\ 1,2,3,4 Sistem Informasi, STMIK Mikroskil \\ email: chatrine.sylvia@mikroskil.ac.id, fandi@mikroskil.ac.id, \\ 162110515@students.mikroskil.ac.id,162112397@students.mikroskil.ac.id
}

\begin{abstract}
The NUFARM application is a mobile application that delivers online aquaculture management services for aquaculture cultivators by providing information / news about aquaculture, cultivated organism's growth monitoring by delivering real-time information about cultivation condition, and providing a marketplace for buying and selling transactions for business entrepreneurs or aquaculture cultivators. several problems have been found in the aquaculture industry which is comprise of the lack of reliable information sources on aquaculture management, the unavailability of media that able to assist farmers on accessing information about the place's conditions and organisms that being cultivated, there is no place for buying and selling transactions specialized on aquaculture for farmers. entrepreneur in the aquaculture business sector. The application design provides various online aquaculture management services which are manifested in the several main features. NUMonitor which provides information about the condition of the organism in real-time (in the form of temperature, dissolved oxygen levels, and pH) for the user. NUFeed which able to feed organisms with variety of settings which is able to be scheduled, automatic feeding and manual feeding. NUPeep which is a camera sensor that able to display organism condition to the user visually. NULight as an additional feature with its function for adjusting the illumination level of for example the aquarium lights. NUShop that serves a place for trading transactions for cultivated organisms and their equipment. As well as the NUpdate feature that able to provide the latest information I news about aquaculture along with tips and tricks for aquaculture management.
\end{abstract}

Keywords: aquaculture, aquaculture management, mobile applications

\section{PENDAHULUAN}

Berdasarkan data yang dikeluarkan oleh Kementerian Kelautan dan Perikanan Republik Indonesia, Pertumbuhan Domestik Bruto (PDB) Perikanan terus mengalami pertumbuhan positif hingga tahun 2018. Pada triwulan III 2018, nilai PDB Perikanan mencapai Rp59.984,3 triliun. Angka ini bertumbuh 3,71 persen jika dibandingkan PDB Perikanan pada tahun sebelumnya di periode yang sama dengan capaian Rp57.838,0 triliun [1]. Selain itu berdasarkan tabel "Jumlah Perusahaan Budidaya Perikanan Menurut Jenis Budidaya" yang dikeluarkan oleh Badan Pusat Statistik (BPS), pada tahun 2017 telah ada sejumlah 257 perusahaan budi daya perikanan di Indonesia yang merupakan gabungan dari jenis budi daya perikanan yang berupa tambak, pembenihan, air tawar, dan laut [2]. Fakta ini memperlihatkan bahwa budi daya perikanan di Indonesia terus meningkat pesat dan menjadikan sektor perikanan sebagai peluang bisnis yang menjanjikan. Adanya peluang ini membuat pengusaha budi daya perikanan di Indonesia, perlu melakukan pengelolaan yang baik agar bisnis tidak surut. Untuk mendukung peningkatan dalam sektor bisnis ini, sebuah wadah diperlukan untuk memfasilitasi transaksi jual-beli agar dapat membantu pengusaha dalam memperluas bisnis yang mereka kelola.

Beberapa hal perlu diperhatikan dalam budidaya untuk menghasilkan jenis dan kualitas ikan yang unggul dan baik, di antaranya adalah pemilihan benih ikan yang akan dibudidayakan, pemberian pakan yang sesuai dan terjadwal, dan 
kualitas air pada habitat ikan. Pemilihan benih ikan sangat bergantung kepada sistem budi daya yang akan ditetapkan. Misalnya pada budi daya ikan mas di kolam air deras, ukuran benih yang dapat digunakan sebaiknya berukuran 100 gram/ekor. Untuk pakan, setiap jenis ikan mempunyai jenis makanan dan jadwal yang berbeda. Pakan yang diberikan untuk ikan mas adalah pakan alami, pakan buatan dan pakan tambahan. Selain itu, pengelolaan kualitas air juga penting sehingga memenuhi persyaratan hidup bagi jenis ikan yang akan dibudidayakan. Variabel kualitas air yang sangat berpengaruh pada ikan mas antara lain: suhu air, kadar oksigen terlarut, kadar $\mathrm{CO} 2$, volume air, dan kekeruhan air [3], [4]. Namun, ini merupakan masalah yang dihadapi pembudidaya yaitu belum adanya media yang memberikan informasi mengenai variabelvariabel tersebut (suhu air, kadar oksigen terlarut, dan $\mathrm{pH}$ ) secara rutin.

Selain ikan, di dalam budi daya perikanan terdapat juga organisme air lainnya seperti udang, kerang, dan tanaman air. Pemberian pakan udang juga perlu diperhatikan seperti halnya ikan karena udang mempunyai kebiasaan makan pada malam hari. Aktivitas makan udang meningkat pada hari gelap sehingga menjelang sore jumlah pakan relatif lebih banyak [5]. Tidak semua pembudidaya mengetahui hal tersebut karena minimnya sumber informasi terpercaya tentang budi daya perikanan (akuakultur).

Masalah-masalah di atas dapat menghambat perkembangan budi daya perikanan (akukultur) di Indonesia sehingga dibutuhkan suatu layanan pengelolaan akuakultur yang tidak hanya mencakup untuk budi daya ikan saja, tetapi termasuk organisme air lainnya yang dibudidayakan di lingkungan akuakultur seperti budi daya udang, budi daya kerang, dan budi daya tanaman air. Oleh karena itu, penelitian ini ditujukan untuk menghasilkan layanan untuk mendukung pengelolaan akuakultur dalam bentuk aplikasi berbasis mobile.

\section{METODE PENELITIAN}

Metode yang digunakan untuk merancang aplikasi mengacu pada metodologi System Development Life Cycle (SDLC) sebagaimana yang dapat dilihat pada gambar 1, dengan rincian tahapan sebagai berikut [6]:

1. Mengidentifikasi masalah, peluang, dan tujuan

Pada tahapan ini, penulis mengidentifikasi masalah-masalah yang sering dihadapi oleh para pembudidaya akuakultur, mengidentifikasi peluang yang dapat ditawarkan untuk peningkatan kualitas budidaya perikanan yang dapat didukung oleh aplikasi, serta kemudian menetapkan tujuan perancangan aplikasi.

2. Menentukan syarat-syarat informasi

Pada tahapan ini, penulis mengkaji masalah yang telah diidentifikasi pada tahap sebelumnya secara lebih lanjut untuk kemudian menentukan syarat-syarat informasi yang penting untuk rancangan.

3. Menganalisis kebutuhan-kebutuhan sistem

Tahapan ini melibatkan kegiatan analisis kebutuhan fungsional yang dimodelkan dengan menggunakan Use Case Diagram.

4. Merancang sistem yang direkomendasikan

Tahapan ini merupakan tahapan perancangan aplikasi mobile dengan menggunakan Just In Mind. Sementara itu, untuk perancangan website admin menggunakan HTML, CSS dan Bootstrap.

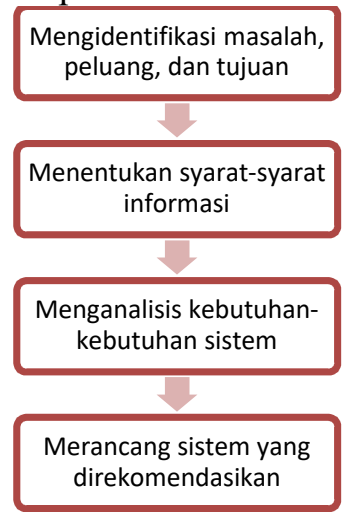

Gambar 1. Tahapan Penelitian

\section{HASIL DAN PEMBAHASAN}

Diagram Fishbone atau yang disebut juga Diagram Ishikawa dikembangkan pada awal 1940-an oleh Dr. Kaoru Ishikawa dari Universitas Tokyo. Seperti namanya, diagram fishbone berbentuk seperti kerangka ikan. Dimana kepala ikan adalah masalah yang ingin dicari sebab akibatnya. Tulang dalam diagram fishbone yang merupakan sebab akibat dari 
masalah terdiri dari lima tulang yang sering juga disebut sebagai 5M [7], [8]. Analisis masalah untuk kegiatan perancangan ini dimodelkan dengan menggunakan Diagram Fishbone dengan gambar sebagai berikut di bawah ini.

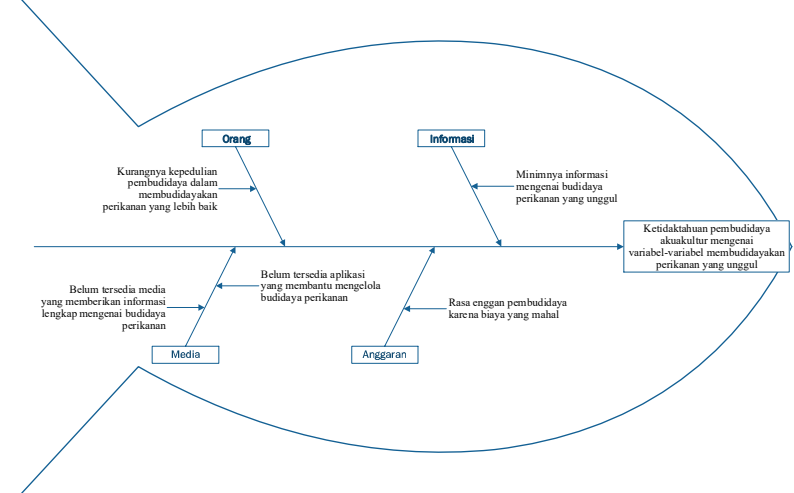

Gambar 2. Diagram Fishbone Analisis Masalah

Use case modeling/pemodelan use case adalah pendekatan yang digunakan untuk menfasilitasi pengembangan dengan berpusatkan kegunaan sistem. Use case modeling adalah proses pemodelan fungsi-fungsi sistem dalam konteks peristiwa-peristiwa bisnis, siapa yang mengawali, dan bagaimana sistem melakukan respon [9], [10]. Kebutuhan fungsional aplikasi yang dirancang dimodelkan dengan Use Case Diagram yang digambarkan sebagai berikut.

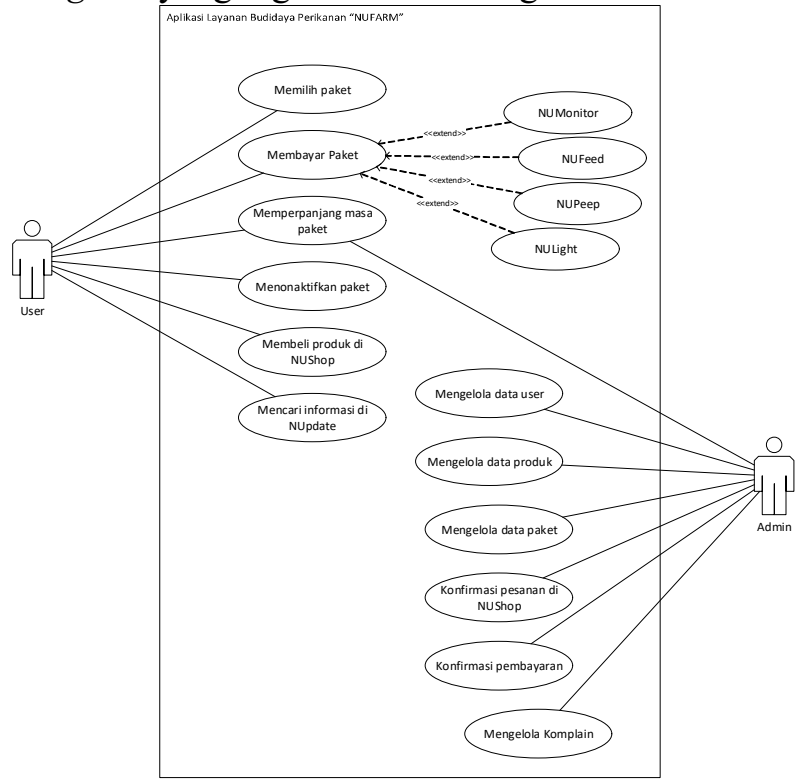

Gambar 3. Diagram Use Case

NUFARM adalah aplikasi mobile yang menyediakan layanan dalam pengelolaan budi daya perikanan (akuakultur). Akuakultur meruapakan nama lain dari budi daya perikanan yang selain berisi tentang budi daya ikan saja juga dapat berupa budi daya organisme air lainnya seperti udang, kerang, dan tanaman air seperti rumput laut. Melalui aplikasi ini, pembudidaya dapat memantau kondisi tambak atau akuarium dengan penyediaan monitor yang disertai dengan penggunaan sensor alat/perangkat IoT (Internet of Things). Selain layanan monitor organisme akuakultur, NUFARM juga dirancang sebagai media transaksi jual-beli bagi para pembudidaya, dirancang sebagai media penyebaran berita dan informasi (tips dan trik) seputar akuakultur. Tampilan untuk pengguna (user) dirancang berbasis aplikasi mobile, sementara tampilan admin dirancang berbasis website.

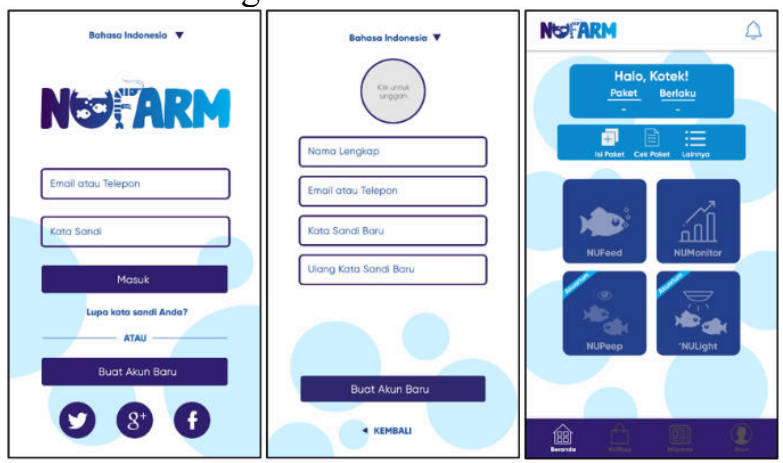

Gambar 4. Tampilan Login, Register dan

Beranda

Akun NUFARM dirancang untuk dapat diakses melalui beberapa cara, yakni: melalui email atau nomor telepon, melalui akun sosial media Twitter atau Facebook atau akun Google. Setelah login atau register akun NUFARM, pengguna dapat mengakses tampilan Beranda yang berisikan beberapa fitur utama NUFARM seperti NUMonitor, NULight, NUFeed, dan NUPeep. Beranda juga menampilkan paket pengguna yang sedang digunakan oleh user dan durasi masa berlakunya paket.

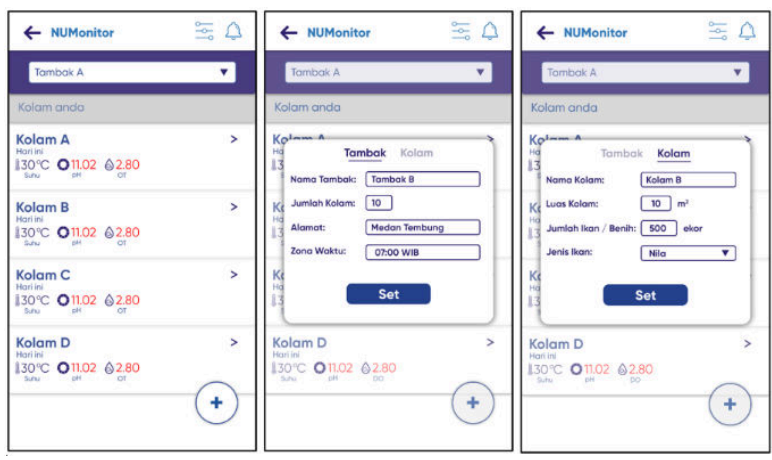

Gambar 5. Tampilan NUMonitor 
Pada Gambar 6 sebagai rancangan tampilan awal NUMonitor, pengguna akan disajikan daftar kolam yang sudah ditambahkan sebelumnya. Pengguna juga dapat melihat grafik untuk memastikan kolam memiliki tingkat suhu, $\mathrm{pH}$, maupun kadar oksigen dalam air yang stabil. Selain itu, pengguna dapat mengatur grafik yang hendak ditampilkan dengan filter data berdasarkan tanggal, bulan, dan tahun yang diinginkan.

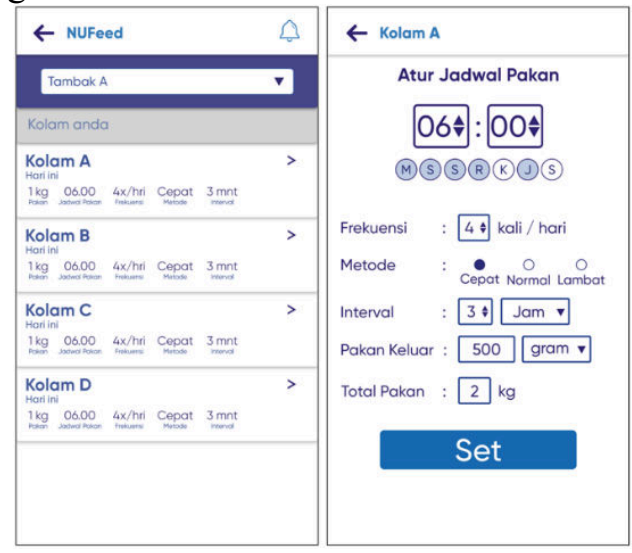

Gambar 6. Tampilan Pemberian Pakan (NUFeed)

Pada Gambar 7 di bawah, aplikasi juga dirancang agar pengguna dapat memberi makan organisme air secara otomatis dengan memilih kolam kemudian menentukan jadwal pemberian pakan yang diinginkan termasuk frekuensi keluarnya pakan pada setiap pemberian pakan dari mesin yang tersedia dalam tiga mode: cepat, normal, dan lambat, serta pengaturan interval pemberian, dan jumlah pakan yang diberikan.
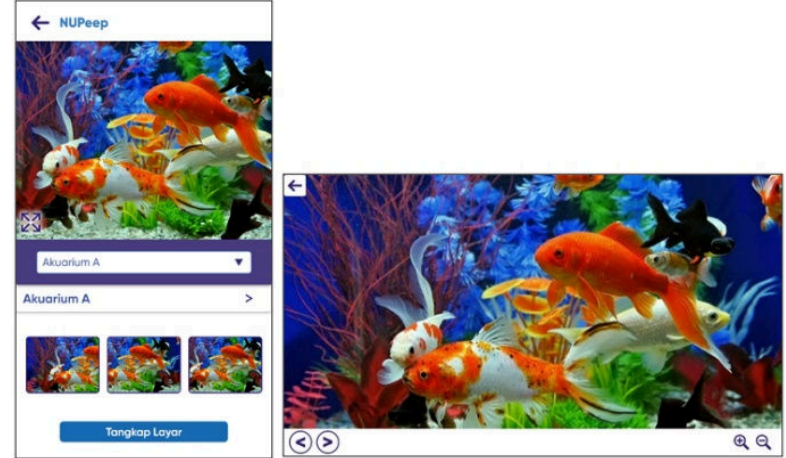

Gambar 7. Tampilan NUPeep

Aplikasi juga dirancang agar oengguna dapat memantau pergerakan ikan mereka secara visual di akuarium melalui fitur NUPeep. Pada tampilan ini pengguna bisa memantau organisme secara real-time dan/atau menggunakan fitur 'Tangkap Layar' (screenshoot).

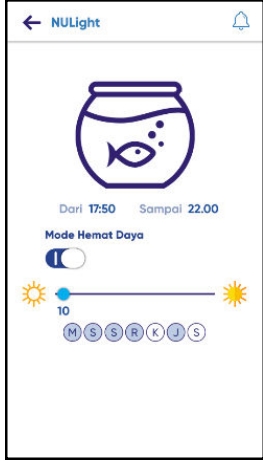

Gambar 8. Tampilan NULight

Gambar 8 menampilkan fitur NULight, dimana pengguna dapat mengatur intensitas cahaya lampu akuarium dari skala 1-100, mengatur jadwal lampu akuarium menyala atau tidak secara teratur berdasarkan waktu yang diinginkan. Selain itu, juga terdapat mode hemat daya yang ditandai dengan redupnya lampu akuarium.

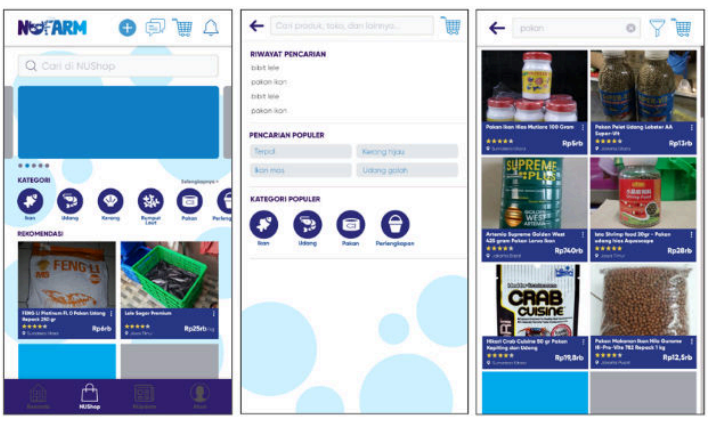

Gambar 9. Tampilan NUShop

Rancangan aplikasi juga mendukung pengguna untuk melakukan pencarian produk dengan menggunakan kata kunci pada kotak pencarian NUShop atau dengan memilih kategori produk yang tersedia pada tampilan awal NUShop. Pada NUShop juga terdapat fitur Filter produk yang memudahkan pencarian produk. Melalui fitur Filter pengguna dapat mempersempit hasil pencarian dengan memilih jenis kategori, rentang harga, lokasi penjual produk, rating, kondisi barang atau produk, serta jasa pengiriman yang tersedia. Pada tampilan Detail Produk NUShop, terdapat deskripsi produk, ulasan dari pembeli lain, kontak penjual, serta kolom diskusi antar pembeli.

Setelah selesai memilih produk dan beralih ari keranjang belanja, pengguna akan dihadapkan dengan tampilan Checkout yang terdiri dari tiga tahapan untuk memproses pesanan produk pengguna, yakni: Pengiriman, Konfirmasi, dan Pembayaran. Pada tahap 
Pengiriman, pengguna akan diminta memasukkan informasi penerima produk, alamat penerima produk, dan jasa pengiriman yang hendak digunakan. Selanjutnya pada tahap Konfirmasi, pengguna diberi kesempatan untuk memeriksa kembali kebenaran informasi penerima, alamat penerima, jasa pengiriman, daftar produk beserta harga, subtotal harga, dan total pembayaran yang harus dibayar oleh pengguna. Pengguna dapat melakukan perubahan dengan mengklik tombol 'Ubah' jika terdapat informasi yang belum sesuai. Akhirnya, pada tahap pembayaran, pengguna dapat memilih metode pembayaran dan mendapat petunjuk pembayaran sesuai metode pembayaran yang dipilih.

NUShop juga dirancang dengan fitur Notifikasi yang dapat diakses pada tampilan awal (Beranda) NUShop yang terbagi menjadi dua: untuk bagian Transaksi dan bagian Informasi. Selanjutnya juga terdapat Tampilan Jual Barang yang ditujukan bagi pengguna dengan peran sebagai penjual di NUShop. Fitur ini dapat diakses pada tampilan awal (Beranda) NUShop. Pengguna hanya perlu mengisi informasi tentang barang atau produk yang ingin dijual yang meliputi: nama barang, kategori, harga, stok, pembelian minimum, berat, kondisi, deskripsi barang, serta menyertakan foto barang atau produk. Terdapat juga fitur Chat yang dirancang sebagaimana fitur Notifikasi NUShop, yang dapat diakses melalui tampilan awal (Beranda) NUShop. Di sini pengguna dapat berkomunikasi dengan penjual maupun pembeli.

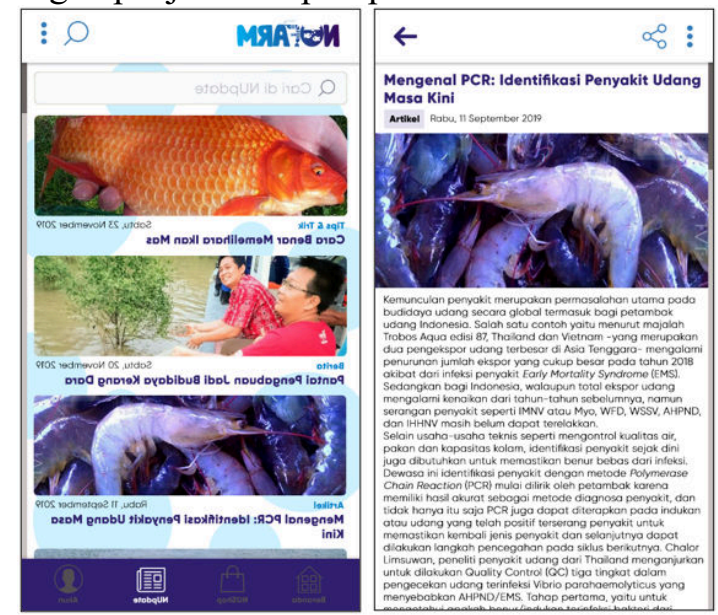

Gambar 10. Tampilan NUpdate

Gambar 10 merupakan tampilan yang menunjukkan bahwa aplikasi NUFARM juga dirancang untuk dapat menyediakan NUpdate agar dapat membantu pengguna mendapatkan informasi/berita terbaru seputar akuakultur beserta tips dan trik untuk mengelola akuakultur.

Aplikasi juga dirancang untuk dapat diakses oleh administrator sistem namun dengan berbasis website. Adapun tampilannya dapat dilihat pada gambar 11 berikut di bawah ini.

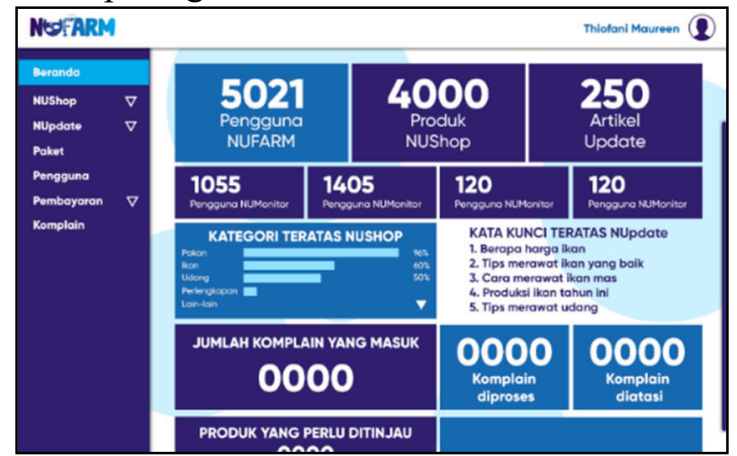

Gambar 11. Tampilan Beranda Admin

Untuk mengakses tampilan admin NUFARM, pengguna harus login terlebih dahulu dengan menggunakan email dan password sebagai admin. Setelah login, pengguna akan diarahkan ke tampilan beranda admin NUFARM. Pada tampilan Beranda admin NUFARM, pengguna dapat mengetahui jumlah pengguna NUFARM, jumlah produk NUShop, jumlah artikel NUpdate, dan informasi lainnya yang diperbarui secara real-time.

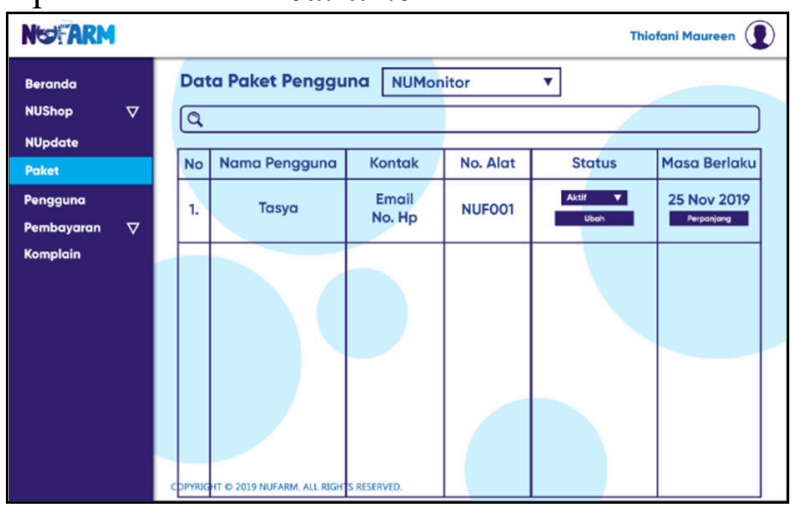

Gambar 12. Tampilan Paket Pengguna

Gambar 12 merupakan rancangan Menu Paket yang berisi data paket pelanggan untuk fitur-fitur utama NUFARM yang terdiri dari NUMonitor, NUFeed, NUPeep, dan NULight. Pengguna dapat menonaktifkan paket jika masa berlaku sudah lewat atau memperpanjang masa berlaku paket. 


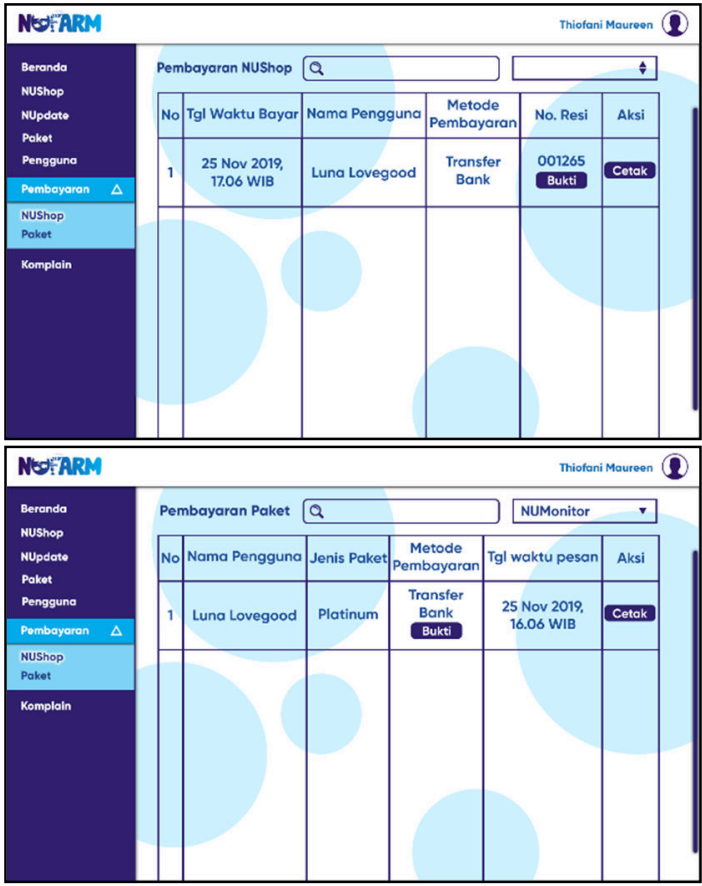

Gambar 13. Tampilan Admin Pembayaran

Submenu NUShop dan Paket

Menu Pembayaran terbagi menjadi dua submenu yaitu pembayaran untuk NUShop dan pembayaran untuk paket. Submenu untuk pembayaran NUShop berisi transaksi yang berhasil dilakukan saat melakukan jual-beli di NUShop. Pengguna dapat melihat dan mencetak bukti pembayaran. Pada submenu untuk pembayaran paket, pengguna dapat memfilter daftar paket berdasarkan fitur yang digunakan, misalnya NUMonitor. Sebagaimana pada submenu untuk pembayaran NUShop, pengguna dapat melihat dan mencetak bukti pembayaran.

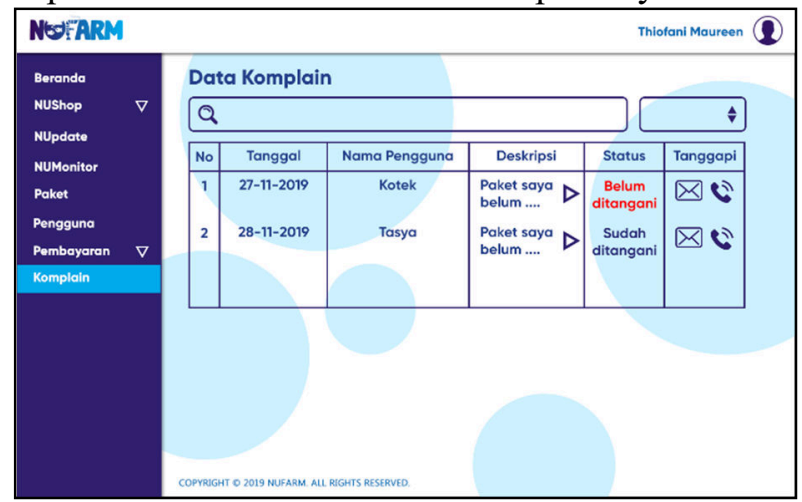

Gambar 14. Tampilan Admin Komplain

Gambar 14 merupakan rancangan Menu admin Komplain yang berisi data komplain dan pertanyaan dari pelanggan NUFARM. Pengguna dapat menanggapi komplain atau pertanyaan yang belum ditangani dengan menghubungi pelanggan melalui email atau telepon.

\section{KESIMPULAN}

Kesimpulan yang dapat ditarik dari kegiatan rancang bangun aplikasi NUFARM ini adalah sebagai berikut:

1. Dapat membantu pembudidaya akuakultur dalam menyediakan informasi/berita terbaru seputar akuakultur beserta tips dan trik untuk mengelola akuakultur.

2. Tersedianya rancangan aplikasi yang memungkinkan pembudidaya akuakultur untuk memantau perkembangan organisme yang mereka budidayakan dan memberi informasi secara real time mengenai kondisi budi daya (kolam/tambak/ akuarium).

3. Apabila dikembangkan menjadi aplikasi maka dapat menjadi fasilitator bagi pembudidaya akuakultur untuk memperjualbelikan produk akuakulturnya.

\section{REFERENSI}

[1] O. KKP RI, "Tunjukkan Pertumbuhan Positif, Kkp Catat Pdb Perikanan Rp 59,98 Triliun," 2018. https://kkp.go.id/artikel/8063-tunjukkanpertumbuhan-positif-kkp-catat-pdbperikanan-rp-59-98-triliun (accessed Oct. 15, 2020).

[2] B. Badan Pusat Statistik, "Subjek Perikanan."

https://www.bps.go.id/subject/56/perikan an.html\#subjekViewTab1 (accessed Oct. $15,2020)$.

[3] Gusrina, Budidaya Ikan Jilid 1 untuk SMK. Jakarta: Direktorat Pembinaan Sekolah Menengah Kejuruan, 2008.

[4] D. Azhari and A. M. Tomasoa, "Kajian Kualitas Air dan Pertumbuhan Ikan Nila (Oreochromis niloticus) yang Dibudidayakan dengan Sistem Akuaponik," Akuatika Indones., vol. 3, no. 2, 2018, doi: 10.24198/jaki.v3i2.23392.

[5] Gusrina, Budidaya Ikan Jilid 2 untuk SMK. Jakarta: Direktorat Pembinaan Sekolah Menengah Kejuruan, 2008. 
[6] K. E. Kendall and J. E. Kendall, Systems Analysis and Design, Ninth Edit. New Jersey: Pearson Prentice Hall, 2014.

[7] Kuswandi, Novianta, and D. Mafazi, People Development Handbook. Hasfa Publishing, 2018.

[8] D. Cotton, The Smart Solution Book: 68 Tools for Brainstorming, Problem Solving, and Decision Making. Elex Media Komputindo, 2017.

[9] J. L. Whitten, L. D. Bentley, and K. C. Dittman, Systems Analysis and Design Methods., 7th Editio. New York: McGraw-Hill/Irwin, 2007.

[10] A. Modelling, "UML 2 Use Case Diagramming Guideliness," 2003. http://www.agilemodeling.com/style/use CaseDiagram.htm (accessed Jan. 25, 2021). 